\title{
El instinto territorial y su orientación
}

\section{Qué es el instinto territorial}

Aunque constantemente se oye hablar, en los medios de comunicación social, de autonomías, regionalismo, autodeterminación de los pueblos y defensa del propio territorio nacional o estatal, pocas veces se hace alguna indicación respecto a las raíces apropiadas o posibles fundamentos de tales fenómenos, notabilísimos en nuestros días.

En concreto solamente entre especialistas se cita el instinto territorial como algo importante al respecto. Aun los trataditas de ecologismo no tocan demasiado el tema, quizá tabuizado por sus antepasados extremistas. Con frecuencia los traductores envuelven dicha expresión en un halo poético psicologista, doméstico, al convertirlo en instinto de dominio ${ }^{1}$. Así el lector cree estar ante un escrito de un discípulo de Adler o de Nietzsche relativo a la voluntad de poder o de dominación, aun cuando muy poco tenga que ver con ello.

Por tanto, parece necesario tratar abiertamente el problema acerca de la existencia o no de un instinto territorial en el hombre y sus posibles consecuencias.

En primer lugar convendría definir lo que sea un territorio o un instinto territorial para ver después si es posible afirmar un instinto territorial humano o no. R. Ardrey dice así: «Territorio, en sentido ecológico, es el espacio, sea acuático, terrestre o aéreo, que un animal o grupo de animales defiende como reserva primitiva suya. Y se denomina territorialismo la compulsión interna que mueve a los seres animados a poseer y defender tal espacio» ${ }^{2}$.

1. Es el caso de la traducción castellana de la obra: ARDREY, R., The territorial imperative. Trad. castellana de H. Rodríguez Suárez. Hispano Europea, Barcelona 1970. Lo que no obsta para que la palabra dominio pueda ser técnicamente muy buena por su relación con la domus y su espacio vital.

2. ARDREY, R., Ibid., 1. 
Como se ve se trata de la existencia:

- de un lugar o zona determinada.

— defendido, en ese sentido apropiado, por un animal o grupo de animales.

Aunque se discuten las interpretaciones de Ardrey sobre el instinto territorial, su definición es, en general, aceptada por todos los autores, sin grandes problemas. Así, G. di Siena, aunque le critica duramente sus afirmaciones, copia su definición de territorio o instinto territorial ${ }^{3}$. También A. Storr ${ }^{4}$ recoge la misma definición. Según K. Lorenz, los animales luchan por su territorio y «el vencido huye del territorio del vencedor y éste no le persigue» ${ }^{5}$. Pero el nuevo dueño expone por el color, el canto u otro medio «un furioso empeño en la defensa del territorio» ${ }^{6}$.

Esta defensa a veces se organiza en grupo; y es espectacular en los mamíferos bien armados. Y a vida o muerte entre los pobres cercados e indefensos. Precisamente y según Lorenz, la habilidad del domador de circo se cifra certeramente en el instinto territorial: saber cuándo el animal optará por la huida y el abandono o se verá sin salida y atacará.

La defensa de un territorio puede tener razones económicas y a la vez es: El espacio que determinado grupo animal, o humano, necesita para su subsistencia y distribución apropiada sin generar excesivos conflictos. También puede relacionarse el territorio con la sobrevivencia y permanencia familiar: La relación entre victoria territorial y posibilidad mayor de reproducción sería un medio del ecosistema por el que el animal con mayor probabilidad de supervivencia transmite sus mejores posibilidades ${ }^{7}$. Eso no quiere decir que los demás no tengan posibilidad de reproducirse, a su vez, como a veces parecen sobreentender ciertas interpretaciones elementales y extremistas, puesto que la fuerza física no es lo único que cuenta.

Sólo en circunstancias excepcionales, vgr., de cautividad, es cuando las luchas territoriales «pueden tener consecuencias destructoras» ${ }^{8}$. Por eso, según Lorenz, el instinto territorial no tiene nada que ver con el instinto de muerte freudiano aunque la agresión se pueda sustituir por el aburrimiento.

3. Di SienA, G., Ideologie del biologismo. Trad. castellana de F. Caviano y C. Pleyán. Anagrama, Barcelona, sin fecha, 10.

4. Storr, A., Human Aggression. Trad. castellana de J.R. Capella. Alianza, Madrid $1979^{2 a}, 63$.

5. LOREnz, K., Das sogenannte Böse. Trad. castellana de F. Blanco y A. Suárez, S. XXI ed., Madrid 1971, 22.

6. LORENZ, K., Ibid., 29.

7. LORENZ, K., Ibid., 39.

8. LORENZ, K., Ibid., 58. 
En general, la disminución excesiva del territorio lleva consigo una acumulación desorbitada de la agresividad. Tales circunstancias hacen que cualquier estímulo agresivo se multiplique entonces de forma descomunal. Otras veces puede llegar a provocarse, por falta de espacios apropiados, auténticas enfermedades psicológicas e incluso biológicas según es conocido en los casos de reducción de grupos prístinos dispersos a poblados. No todo se explica ahí por las bacterias. Asimismo la posibilidad de espacios excesivos provoca verdadera desorientación en los animales y en los hombres. Los seres se sienten en esta situación como perdidos, no encuentran su lugar de cobijo y descanso, ni habitat apropiado, de modo que se mueven sin parar de un lado para otro hasta encontrar su nido o rincón propio.

Un efecto básico y muy conocido del instinto territorial es que «la posesión de un territorio presta al propietario acrecentada energía» ${ }^{9}$. En su territorio, el animal multiplica sus fuerzas ostensiblemente. Además parece que el intruso reconoce, en cierto modo, su culpa. Parece indudable que hay «un cierto reconocimiento universal de los derechos territoriales» ${ }^{10}$. Un ejemplo, más o menos vulgar, de esto es la conocida ventaja de «jugar en casa».

\subsection{La demarcación territorial}

Los animales marcan sus territorios y los señalan de muy distintas maneras, con el fin de evitar peleas con los intrusos. Las formas más notables de esta demarcación son:

- La ostentación de sus colores que advierten al vecino o posible intruso de que allí hay un poblador serio y decidido. Todas las fronteras exigen banderas, son señales visuales.

- También el canto es una forma de señalización territorial. Se trata de signos auditivos. El admirable canto del ruiseñor «que, como dice acertadamente Ringelnatz, 'obligó a los poetas a ponerlo en verso'... sirve para advertir a sus congéneres y solamente a ellos - que tal territorio ha hallado un dueño definitivo y dispuesto a pelear por él» ${ }^{11}$. La misma función que el canto tienen otras señales sonoras como alaridos, aullidos, el acto de bramar, etc.

-El olor es igualmente un medio de demarcación. Algunos animales marcan con productos de glándulas especiales su territorio propio. Los lobos lo hacen además por medio del orín, igual que otros animales: «Mediante la se-

9. ARDREY, R., The territorial, 1.

10. ARdREY, R., Ibid., 2.

11. Lorenz, K., Das sogenannte, 29. Y en otros escritos de Lorenz. 
ñalización de los límites, reducen los lobos la probabilidad de un conflicto mortal sobre los derechos de propiedad $»{ }^{12}$.

Hay otras muchas maneras de delimitar el territorio, a veces difíciles de clasificar. Puede añadirse ya que el hombre también marca su territorio de formas diversas. Así los pueblos antiguamente establecían su territorio por las campanas y la lejanía de su doblar. De ahí las coplas a favor y en contra de las campanas de los pueblos limítrofes ${ }^{13}$. Las fronteras, el piso, el coche son otras tantas formas de demarcación. El derecho protege asimismo la inviolabilidad del domicilio.

La adolescencia y la inmadurez sexual del animal nuevo, gèneralmente, hace menos urgente la territorialidad. Esas edades son por lo mismo muy apropiadas para el merodeo, la exploración de rincones en la casa y el pueblo y el vagabundeo en cuadrillas. Las peleas son también aquí más bien rituales que serias y se desarrollan sobre la tierra de nadie abandonada al mundo juvenil. Pero como dice Tinbergen: «Más tarde, sin embargo, maduraron sexualmente y en seguida aprendieron a reconocer sus límites territoriales» ${ }^{14}$.

Al hablar de la efebía y el status del adolescente en la sociedad griega, P. Vidal-Naquet hace unas observaciones muy concordes con los principios expuestos al hablar de «la estancia de los efebos en los fortines fronterizos» ${ }^{15}$. Cuando se merodea aún no se es maduro y formal. El territorio apropiado es lo que da validez y madurez definitiva a la fecundidad. Cada uno debe aprender su territorio y el de sus oponentes, a quiénes debe combatir y a quiénes no; ahora-bien, el que haya de aprenderse no quiere decir que no sea innato e instintivo. En efecto, después de varias investigaciones de campo en el Congo y Uganda, Ardrey concluye: «Nos encontramos aquí con un instinto abierto cuyo componente final, regulado por un patrón genéticamente determinado, se realiza por medio de la tradición social y la experiencia individual» ${ }^{16}$.

Para Ardrey el territorio es primero, de modo que se compite por él en primer lugar y no por las hembras, como suele afirmarse. Según Howard: «Se trata del territorio. Todo gira alrededor de esto. Territorio, Territorio! (sic)» ${ }^{17}$. Existe por lo tanto en los animales el 'instinto llamado territorialismo' o instinto territorial. Esa fuerza del territorio que podemos llamar telúri-

12. ARDREY, R., The territorial, 9.

13. Velasco, H., Simposio nacional de Antropología de Barcelona, 1976. En algunos pueblos se cumple la lucha entre vecinos con la rotura de campanas y de esto hay ejemplos recientes en la provincia de León.

14. El pensamiento es de N. Tinbergen pero lo recoge ARDREY, R., The territorial, 27.

15. VIDAl-NAQUET, P., «El cazador Negro». Formas de pensamiento y formas de sociedad en el mundo griego. Península, Barcelona 1983, 176.

16. ARDREY, R., The territorial, 51.

17. Citado por ARDrey, R., Ibid., 65. 
ca, es como electrizante. Mediante ella se cumple una ordenación territorial y una escala social ${ }^{18}$. Según Ardrey este instinto territorial es mucho más fuerte que el sexual y por eso «el casado casa quiere».

\subsection{Entonces ¿tiene el hombre un instinto territorial?}

En efecto, nos dice A. Storr: «No cabe duda de que también el hombre es un animal territorial» ${ }^{19}$. De hecho, continúa el mismo autor, la entrada en el domicilio ajeno, o de un extraño en el jardín de la casa de otro, sin permiso, se considera como una pérdida de un bien supremo y el derecho de las naciones protege la inviolabilidad del propio domicilio.

La reducción del propio territorio por la aglomeración ciudadana provoca todo tipo de problemas y agresiones. Por ello probablemente se elogia la paz del campo: «la población rural es (sea) menos tensa, más amistosa y con frecuencia menos brusca que su contrapartida urbana» ${ }^{20}$. Para $\mathrm{H}$. Hediger, el instinto territorial en el «reino animal representa el primer capítulo de la historia de la propiedad en la humanidad» ${ }^{21}$. El reconocimiento del derecho a un territorio propio es tradicional en la historia de la humanidad y por tanto: «Que la naturaleza territorial del hombre es ingénita y de origen evolutivo, difícilmente es una idea nueva; es meramente una idea ignorada» ${ }^{22}$.

Esa es la razón, según Lorenz, por la que seres «sociables y apacibles dentro de su propia tribu (pero) se conducen como verdaderos demonios con los congéneres que no pertenecen a su bando» ${ }^{23}$. Y eso explica también el porqué de la verdad popular a su gran sabiduría de que «cuando se izan las banderas la razón está en las trompetas». Las fronteras del propio territorio deben haber sido amenazadas y «se debe» reaccionar. Tampoco hace falta ser excesivamente perspicaz para sorprenderse a sí mismo marcando el paso cuando se oyen los tambores. En cualquier caso no conviene olvidar que el aumento de fuerza territorial aunque carezca de explicación carece también de medida, por eso ha dicho muy bien D. Lack: «La victoria no corresponde a los más fuertes, sino a los que poseen el derecho, que son, por supuesto, los propietarios del territorio» ${ }^{24}$.

De todo ello hay ejemplos antiguos y persistentes, pero también actuales

\footnotetext{
18. ARDREY, R., Ibid., 79.

19. STORR, A., Human Aggression, 66.

20. STORR, A., Ibid., 67.

21. Citado por ARDREY, R., The territorial, 119.

22. ARDREY, R., Ibid., 119.

23. LORENZ, K., Das sogenannte, 262.

24. Citado por ARDrEy, R., The territorial, 124.
} 
y modernos. Nadie olvida la guerra del Vietnam. Lo normal es que el vencedor sea el más próximo a su casa. También la comida sabe mejor en la propia casa, por eso 'como lo casero, nada' y eso a pesar de que como dicen los británicos 'siempre se cree más verde la hierba del prado ajeno'. Siempre se trabaja mejor, también, en la hacienda propia o en la que se tiene por tal. Es también de un placer inexplicable la vuelta a la casa solariega, como vuelven los animales a su región de origen. Allí están los ancestros propios y se orienta uno mejor.

El territorio vincula y une a otros que por eso son compatriotas, vecinos, etc., que sirven de apoyo y se sienten, a su vez apoyados. El territorio es una ayuda moral básica. Para Allee: «El territorialismo implica sentido de orientación, defensa de un espacio dado o ambas cosas a la vez» ${ }^{25}$ ¿No influirá lo suyo en la desorientación moral del hombre actual el cambio continuo de territorio, por la movilidad fabulosamente acelerada de las comunicaciones sociales?

El territorio propio, en cambio, ofrece diversos lugares, privados y públicos, donde se puede estar seguro y tranquilo. Naturalmente, en cualquier caso, hay que guardar las distancias, pronto veremos por qué. Si además se tienen enemigos comunes a los que detestar, la seguridad es perfecta. Aunque la cosa aún mejora, cantidad, si se da una autoridad visible. Lorenz define el nivel de cohesión de un grupo por esos tres elementos:

- territorio común bien definido para defender,

-enemigo bien visible,

- autoridad clara.

El segundo elemento explica muy bien por qué frecuentemente triunfa mejor el que insulta más que los otros y recoge también más fácilmente las simpatías del vecindario. Incluso puede ocurrir con cierta frecuencia que: «Furibundamente, tal vez se tenga necesidad del grupo para servirse de él, disponiendo de individuos de la misma especie con los que ponerse furioso» ${ }^{26}$. Finalmente había observado Ortega que nada irrita tanto al hombre de partido (partidista) como el que uno no se aliste al suyo o al contrario.

La práctica de la rivalidad es una de las actividades más características del hombre y no solamente entre las bandadas adolescentes ${ }^{27}$. Por eso un signo definitivo de madurez es el haber superado decididamente esta etapa de fastidiar más bien a los amigos y vecinos. Nunca falta quien espera cuidadosamente la llegada de alguien con quien irritarse como el mono callicebus: «Hombro a hombro, padre y madre esperan, las colas entrelazadas, acariciando sus ren-

25. Citado por ARDREY, R., Ibid., 156 .

26. ARDREY, R., Ibid., 204.

27. GiraRd, R., La violence et le sacré. Grasset, Paris 1972, 121. 
cillas, rumiando sus animosidades, impacientes por la llegada de sus caros enemigos» ${ }^{28}$.

Y sin embargo, una vez hechos algunos alardes espectaculares, no es preciso que la cosa pase a mayores. En cierta manera, también las pequeñas rivalidades forman parte de la trama cotidiana de la vida y en último término «es posible sobrevivir con un mínimo de confianza social, honradez personal, acción concertada y efectiva simpatía» ${ }^{29}$.

Pero sin un territorio propio, sin un habitar en común, el amor se vuelve volátil, se desvanece, dispersa y deshace. Sin esta habitación propia tampoco la vida de la pareja es posible como lo ha demostrado el arquitecto R. Neutra. Sin el instinto territorial tampoco sería posible el patriotismo. Éstas son las afirmaciones rotundas de Ardrey: «Yo mantengo la opinión, por supuesto, de que la continuidad de la evolución humana desde el mundo del animal al mundo del hombre garantiza que un grupo humano, en posesión de un territorio social, se comportará de acuerdo con las leyes universales del principio territorialista. En otras palabras, lo que llamamos patriotismo es una fuerza calculable que liberada por una situación previsible, excitará al hombre de manera no diferente que a otras especies territoriales» ${ }^{30}$.

La cita anterior es suficientemente contundente para que necesite mayores explicaciones. Pero habrá que seguir adelante para tener una relación más reposada y adecuada de todos los aspectos del problema. Puede adelantarse que, según el mismo Ardrey, el principio territorial es como un volcán, rompe todo molde o previsión $y$, en principio, por una parte carece de toda ética mientras que impulsa a todos los seres humanos ${ }^{31}$. Cuando aparece en nosotros constituye un deber sagrado, mirado en los extranjeros le llamamos fanatismo. En efecto, una guerra no se hace entre tenderos o simplemente por razones económicas. Una misma fuerza, el instinto territorial impulsa al ministerio de la defensa y a los propietarios del territorio. Y esto es suficiente para crear graves inconvenientes al enemigo más poderoso. Eso se ha demostrado en distintas ocasiones históricas del pasado, pero puede escucharse una voz más actual: «Los socialistas dicen que la cuestión nacional divide a la clase obrera en el norte, por tanto la cuestión nacional es una cuestión contrarrevolucionaria, por lo que deberíamos impulsar reivindicaciones económicas susceptibles de unificar a la clase obrera... Puedo decirte que todos los intentos

28. ARDREY, R., The territorial, 213.

29. ARDREY, R., Ibid., 221.

30. ARDREY, R., Ibid., 273.

31. ARDREY, R., Ibid., 278. 
que ha habido de no considerar la cuestión nacional y centrarse en la cuestión económica han sido un fracaso» ${ }^{32}$.

Como se ve, aquí, la teoría marxista de la infraestructura económica como motor de la revolución queda orillada. La discusión entre nacionalistas y partidos obreros sigue en varios lugares. No hace falta exponer la convergencia de territorialismo y nacionalismo por ser evidente. Pero, sigamos adelante...

El hombre defiende hasta con la guerra su propio territorio. Los problemas se agolpan sobre todo en las proximidades de las fronteras. Aquí se da también, para bien y para mal, el espíritu heroico, con sus «acciones sociales de carácter defensivo, adoptadas de estricto acuerdo con la ley territorial, que derivan de un profundo instinto, la increíble magnitud de su energía» ${ }^{33}$. Defender el espacio propio es la clave del instinto territorial. Y por muy importante y fuerte que sea el invasor, lo normal es que siempre pierde. Al fin triunfa y se impone el reconocimiento de un derecho. Niko Tinbergen se vio obligado a escribir después de repetidos experimentos y observaciones: «Los transgresores (del territorio ajeno) son la personificación de una conciencia culpable; los propietarios territoriales, de una justa indignación» ${ }^{34}$.

Por supuesto que no hay sólo territorio como no hay sólo economía o sexualidad o rivalidad o mimetismo en la vida humana, pero se debe ahondar en el estudio del instinto territorial.

Freud al explicar las rivalidades entre países vecinos como España y Francia o Portugal y España lo hacía por aplicación de la teoría del narcisismo. El parecido entre pueblos y personas hace que éstas teman más las posibilidades competitivas del vecino y por eso también rivalizan más con él. Es Ardrey el que cita los textos de Freud al respecto procedentes de la Introducción al Psicoanálisis y de El Malestar en la Cultura. Concretamente éste: «En otro tiempo me interesé por el hecho tan peculiar de que los pueblos cuyos territorios son limítrofes y son, por otra parte, estrechamente afines, andan siempre a la greña, y escarneciéndose entre sí, como, por ejemplo, los españoles y los portugueses, los alemanes del Norte y los del Sur, los ingleses y escoceses y así sucesivamente. Le di el nombre de 'narcisismo con respecto a diferencias secundarias', lo que no hace mucho para explicarlo» ${ }^{35}$.

Como se ve ni Freud mismo cree demasiado en su explicación. Ahora te-

32. REDO, J., «Atravesar el infierno para alcanzar la libertad». Entrevista con Bernardette Devlin. El viejo topo, 44 (1980) 16. Subrayado mío.

33. ARDREY, R., The territorial, 288.

34. Tinbergen, N., El estudio del instinto. Citado por Ardrey, R., The territorial, 297.

35. Citado por ARDREY, R., The territorial, 345. 
nemos la explicación a partir del instinto territorial: «Se ha apuntado anteriormente que el hombre es un animal territorial $y$, por consiguiente, posee gran cantidad de hostilidad innata hacia el vecino» ${ }^{36}$. Por eso quien más irrita es el vecino aunque la enemistad es «el oro del mercado de la amistad». En cualquier caso el territorio resulta unificador y unitivo para los propietarios del mismo. La agresividad es por lo mismo en gran parte la consecuencia de los menesteres territoriales. Y en definitiva, como concluye David E. Davis: «Una amplia variedad de observaciones sugiere que la lucha por la posición o el territorio tiene caracteres innatos» ${ }^{37}$.

El territorio ofrece y da al hombre identidad propia; estímulo para desarrollar su vida individual y comunal, y seguridad frente a la intemperie. Según Ardrey «la apetencia de identidad es la más poderosa y penetrante en todas las especies» ${ }^{38}$. La búsqueda de estimulación y seguridad le van a la zaga pero no lejos. Así el principio territorial constituye, según el mismo autor, «la ley biológica sobre la cual hemos cimentado los edificios de la moralidad humana» ${ }^{39}$. Con un espacio propio todas las cosas son mejores.

\subsection{Pero ¿posee el hombre un espacio o territorio propio?}

E. Hall describe varios tipos de espacio humano que, con cierta simplificación, pueden reducirse a tres fundamentales:

1. Espacio íntimo. Es la distancia del acto de amor y de la lucha, de la protección y el confrontamiento. Predominan en la conciencia de ambas personas «el contacto físico o la gran posibilidad de una relación física» ${ }^{40}$. Como se ve la distancia interpersonal en este tipo de espacio es prácticamente nula. Es el territorio apropiado a aquellas actividades de la vida humana cuya realización pública se consideraría anormal. Es el espacio propio del nido y el que las personas defienden con toda su alma. Este territorio constituye el centro del 'hogar, dulce hogar' y cualquier ataque o intromisión en él se considera propio de sinvergüenzas y una violación de los derechos humanos más fundamentales.

2. Espacio personal. Aquí hay una cierta distancia entre las personas, y puede oscilar entre una separación de medio metro hasta un metro y medio. Es el espacio propio de las relaciones interpersonales no íntimas sino ordina-

36. STORR, A., Human Aggression. 71.

37. ARDREY, R., The territorial, 371.

38. ARDREY, R., Ibid., 394.

39. ARDREY, R., Ibid., 412.

40. HaLl, E., The hidden dimension. Trad. castellana de eds. S. XXI, Madrid $1976^{2^{\mathrm{a}}}, 143$ y ss.; aunque la traducción no es excesivamente cuidada se puede considerar válida. 
rias no puramente convencionales. En efecto: «Los asuntos de interés y relación personal se tratan a esta distancia» ${ }^{41}$. No se trata de relaciones íntimas. La voz es clara y no se puede romper esta distancia ni acercarse excesivamente una persona a otra, pues eso sería considerado como una grave falta de educación. A esta distancia un poco aumentada la llama Hall distancia social porque suele ser la que se adopta en las relaciones sociales con cierto interés donde hay participación y relación verdaderamente humana pero no contacto.

3. Espacio público. Es el más convencional. Los individuos se encuentran a distancias notables, entre 4 y 10 metros. Los detalles fisionómicos de las personas ya no son propiamente significativos. La voz pierde su carácter interpersonal, es fría y puramente convencional ${ }^{42}$. Se trata de una envoltura tenue que mantiene unido al grupo. Más allá de este espacio social la persona se pierde, se diluye y comienza a sentir ansiedad. Este es el espacio de la plaza pública y la vecindad. Después los contornos se borran y se entra en lo desconocido y lo peligroso, de modo que para ir más allá es necesario tomar ciertas precauciones y haber explorado antes el entorno.

Como consecuencia de esas exploraciones y conquistas se forma el espacio social provinciano, regional, nacional, etc. En efecto: «La experiencia más común demuestra la presencia de fenómenos de territorialidad en la convivencia social y sobre todo, en las relaciones internacionales. A Kisth unía el surgimiento del nacionalismo y del espíritu patriótico a los ancestrales impulsos territoriales, muy enraizados en el patrimonio hereditario de la especie humana» ${ }^{43}$.

Conviene observar que no todos los pueblos semantizan del mismo modo sus espacios territoriales. No es lo mismo una puerta en alemán que una puerta entre los americanos. No obstante todos los autores hablan igualmente, por ejemplo, de «distancia crítica» que es aquel lugar del territorio que un ser animal o humano defiende siempre invariablemente. Si se penetra en él, su propietario se volverá infaliblemente agresivo, por mucha fama que ostente de ser pacífico; y no huirá en modo alguno de esta posición aunque le cueste la vida ${ }^{44}$. No hacerlo sería propio de calzonazos. Y eso explica por qué algunos animales sumamente pacíficos se vuelven furiosos en esas circunstancias.

Por lo mismo la casa es un centro de refugio y resistencia tanto como lugar obligado de defensa: «Una casa, así, exige al hombre un heroísmo cósmi- . co. Es un instrumento para afrontar el cosmos... La casa vivida no es una caja -

41. HALL, E., Ibid., 148-149.

42. HALL, E., Ibid., 152 y ss.

43. Di SIENA, E., Ideologie, 33-34.

44. ZimmeR, E.D., «Der Raumsinn». Unsere erste Nature. Kösel, München 1979, 71 y ss. 
inerte. El espacio habitado trasciende el espacio geométrico» ${ }^{45}$. Como recuerda Milosz en La tierra y los ensueños de reposo: "Yo digo, madre mía, y pienso en ti, joh Casa!» ${ }^{46}$. Los espectadores bromean con los suspiros de E.T.: «La casa, ¡mi casa!». Habrá que volver sobre ello.

Aunque las distancias y los espacios territoriales varían, según las distintas culturas: «El primero en ocupar un territorio tendrá en él ciertos derechos adquiridos, y así uno pregunta educadamente antes de ocupar un puesto aún libre en la mesa del restaurante. Felipe y Sommer hicieron experimentos en bibliotecas, sobrepasando las distancias individuales y sentándose como por casualidad justo al lado de personas que estaban allí leyendo. Las víctimas intentaban primero apartarse del intruso. Cuando no podían, levantaban barreras artificiales con libros, reglas y otros objetos» ${ }^{47}$.

El espacio humano, como lugar de despliegue de la vida humana está lleno de significados. Así, respecto al mismo, «estar delante» e «ir adelante» tiene significados positivos como tener claridad, avanzar, etc. En cambio «estar detrás», retroceder, es un contratiempo. La antítesis «derecha» e «izquierda» es aún más clara. El término de lo «derecho» es lo recto, lo correcto, lo bueno, lo conforme a derecho. En cambio lo «izquierdo» es lo tortuoso, lo torcido, lo dudoso, lo malo ${ }^{48}$. En el juicio final del Evangelio los buenos están a la derecha y los malos a la izquierda, ovejas y cabras, respectivamente. Pero ya desde tiempos inmemoriales en las listas pitagóricas, bien conocidas en la historia de la filosofía antigua, ocurre exactamente igual: lo derecho y lo recto, lo izquierdo y lo torcido se corresponden perfectamente. Igualmente la posición de «arriba» se considera superior y buena mientras que «abajo» es lo inferior y malo, lo bajo propiamente. Así lo bueno, el cielo, está arriba mientras que lo malo, el infierno, está abajo. Entre estas polarizaciones está «el centro» que es el lugar más seguro como equidistante de la izquierda y la derecha, del nortearriba y el sur-abajo. Así uno está centrado o de lo contrario no se sabe por dónde se anda y se dice que está descentrado.

En ese lugar central está «la confianza ingenua en el espacio, el estado infantil de seguridad, que en la vida ulterior se puede prolongar en un estado de amparo natural o irreflexivo en la casa y en la patria. El hombre está aquí amalgamado con su espacio, encontrado de manera inmediata» ${ }^{49}$. Pero como 78 y 79

45. BACHELARD, G., La poétique de l'espace. Trad. castellana del F.C.E., México $1975^{2 a}$,

46. BACHELARD, G., La poétique, 77.

47. Eibl-EibeSFeldT, I., Der vorprogrammierte Mensch. Trad. castellana de Alianza ed., Madrid 1977, 105. $57-58$.

48. Bollnow, O.F., Mensch und Raum. Trad. castellana de eds. Labor, Barcelona 1969,

49. Bollnow, O.F., Mensch, 270. 
ese reducto puede ser atacado, se crea el 'dominium' o extensión protectora de la 'domus'-casa. Estos dominios son, primero, propiedades particulares como el jardín y el huerto y luego todo el pueblo unido y la provincia después, luego la región y finalmente la nación y el Estado. Si no se tiene este entorno se es un extranjero, un apátrida y vagabundo. En definitiva, sin un espacio o territorio propios se es lo que se dice, una mala persona: sin hogar, sin patria y $\sin$ ley.

\subsubsection{El hombre y su casa}

De esa perspectiva, y para no pertenecer a un mundo desamparado y $\sin$ vigor ni valor, tenebroso y oscuro, deriva la necesidad o si se quiere la insustituible «tarea de rehacer el amparo mediante la construcción de una casa» ${ }^{50}$. La casa es, sin duda, un lugar privilegiado del espacio y el territorio humano: «Porque la casa es nuestro rincón del mundo» ${ }^{51}$. Es el centro de la vida donde todo hombre tiene un hogar o busca el hogar. De la casa salen y a ella vuelven siempre nuestros sueños. Quien no tiene casa está arrojado en el mundo, no tiene un lugar propio ni apropiado en él. A quien se le quemó la casa se le ha destruido la vida, por eso todo el mundo desea ayudarle, ya que es un desamparado. La casa es albergue de refugio y punto de partida de la vida. En ella se calman las tormentas. Hogar del cariño, la ternura y la curación. Al huésped amigo no se le enseña la propia vida, se le enseña la casa y todo lo demás se sobreentiende. De hecho la casa es tan profunda que «la casa natal está inscrita en nosotros. Es un grupo de costumbres orgánicas» ${ }^{52}$.

En la casa el hombre consigue estabilidad, protección, seguridad, identidad frente a la destrucción y la dispersión: «la casa es imaginada como un ser concentrado. Nos llama a una conciencia de centralidad» ${ }^{53}$. Por eso el que vive en la dispersión no puede aguantar la casa. Tiene la enfermedad de la casa - homesickness-. La casa se le cae encima como se suele decir. Tiene miedo a su soledad, la soledad de la casa y escudriña los sótanos y el desván no vaya a haber algún intruso; no se está seguro de la casa, se duda de sí mismo, y por eso, como dice Jung, cuando se oye ruido en el sótano se va al desván y viceversa. No hay verdadero interés por la casa.

Cuando ocurre todo eso, las profundidades nos aterran: «El sótano es entonces locura enterrada, drama emparedado» ${ }^{54}$. Aunque de por sí la bodega

50. Bollnow, O.F., Mensch, 270.

51. BACHELARD, G., La poétique, 34.

52. BACHELARD, G., Ibid., 45.

53. BACHELARD, G., Ibid., 48.

54. BACHELARD,.G., Ibid., 51. 
es lugar de ensueños y grandes proyectos. De hecho es preciso bajar a los sótanos del alma para enfrentar debidamente el futuro. $Y$ en cualquier caso no se puede tener el sótano como un desván destartalado, igual que está muy mal ser un hombre de un solo piso, como decía J. Bousquet: «Es un hombre de un solo piso: tiene el sótano en el desván» ${ }^{55}$. Eso es confundirlo todo.

Por el contrario, el espacio de la casa es ordenado. Desde él se «vela, vigila o espera». Es como la luz y el origen de todas las cosas, incluso del porvenir, más seguro, como la casa es más segura y sólida que las chozas del pasado. La casa no es pasajera como la cabaña. La casa es nido permanente, la cabaña es sólo refugio del temporal. La casa es la mansión de los seres protectores, del primer espíritu y del primer mundo. Ella guarda y cuida a sus habitantes. En ella se crece y se progresa. Ella guarda la intimidad, fuera de ella el hombre está expuesto.

Desde la casa se sale al mundo y en ella se recoge el hombre para reponerse y fortificarse. Todo habitar tiene resonancias cósmicas. La casa es refugio frente al frío y el calor, la lluvia y la tempestad. Lugar de espera para hacerse y rehacerse, desde la casa se vive el paso del tiempo, la antigüedad y la novedad, nuestro propio pasar. Desde su intimidad, igualmente, descubrimos la nuestra como la interiorización del desierto conduce a «la conciencia de un vacío íntimo» ${ }^{56}$.

En su hogar se recoge el hombre errante y peregrino y sus puertas y ventanas abren y cierran la inmensidad íntima del mundo. Desde el hogar se crea y se recrea el mundo. Todo territorio nuevo recrea la intimidad humana, de ahí las buenas razones del ecologismo. El mundo es reflejo del hombre como lo es siempre la casa. En efecto: «la vivienda se hace expresión del hombre mismo que la habita, una parte de este hombre convertida en espacio» ${ }^{57}$. Y así como el umbral de la casa designa el límite entre el mundo interior y exterior, del mismo modo para el buen habitante cerrar la puerta no es quedar encerrado. Pero sí lo es para el extraño que ha sido cogido en la trampa. No está en su propio lugar. Es un intruso y debe salir como sea, o pueda. De ahí también el sentido de la claustrofobia del invasor, ya que «El mundo está adjudicado y sólo se puede adquirir nuevo espacio a costa de los demás» ${ }^{58}$.

Ahora bien, como los hombres tienen que hacerse con su espacio social, defenderlo y, si conviene, ampliarlo, surgen entre ellos las rivalidades: «La

55. Citado por Bachelard, G., Ibid., 57.

56. BACHELARD, G., Ibid., 243.

57. Bollnow, O.F., Mensch, 141.

58. Bollnow, O.F., Mensch, 229. 
única manera de ganar espacio es quitándoselo a otros... No se puede dudar de este criterio prosaico y realista» ${ }^{59}$.

\section{5. ¿Es el instinto territorial un destino inevitable?}

Esa es la historia corriente de la guerra fratricida, de la lucha entre los pueblos y los hombres pero especialmente entre países vecinos. Naturalmente se argumenta que se precisa un espacio vital nuevo, que la propia tierra patria ha sido hollada, pisoteada y ocupada por el enemigo, lo que justifica, al parecer, todo, sin más, contra el invasor.

Hoy sabemos que existen otras posibilidades. Bollnow cita las Formas fundamentales y el conocimiento de la existencia humana de Binswanger, al respecto, para afirmar que quitar al otro «de en medio para colocarse a sí mismo» no es la única alternativa. La nueva posibilidad, opuesta a la rivalidad, tan característica de la vida humana en especial con referencia al territorio, radica en la vivencia de la «espacialidad del amoroso estar juntos» ${ }^{60}$. Donde hay amor no cabe la rivalidad, la competición ni la violencia. Por el contrario las vidas se fusionan y las demarcaciones de lo tuyo y lo mío se borran. Por eso el hombre violento necesita mucho espacio, y el sujeto agresivo y nervioso va invadiendo los territorios vecinos a troche y moche con el grito, el ruido, la música o simplemente la fuerza. El ruido es un modo de penetrar el espacio ajeno e invadir al vecino, avasallarlo. Por el contrario la aparición del amor borra las fronteras y rompe las alambradas. Y esto ocurre como «la cesión despreocupada, infinita, del espacio uno e indivisible de la 'reciprocidad', del Nosotros infinito, inagotable e insondable del amor» ${ }^{61}$.

Los amantes no hacen vallas, no tienen barreras, su única defensa es el amor como la esperanza no tiene límites. Y así pueden sobrevivir con las mayores limitaciones. V. Frankl lo ha demostrado con su experiencia dramática pero aleccionadora de los horribles campos de concentración ${ }^{62}$. Ciertamente una persona puede sobrevivir en un encierro que volvería loco al animal más pacífico y aterritorial, siempre que puedä brillar en ella de algún modo la más tenue luz de esperanza.

Por tanto el instinto territorial puede ser educado, orientado y humanizado. El amor, en efecto, constituye una amplificación infinita del espacio humano donde todos los horizontes se funden para formar un nuevo mundo sin fronteras. Así, «en lugar de desbancar al 'otro' desposeyéndole de su sitio en

59. Bollnow, O.F., Mensch, 228.

60. Bollnow, O.F., Mensch, 229.

61. Citado por Bollnow, O.F., Mensch, 229. na 1980

62. FrankL, F.,El hombre a la búsqueda del sentido. Trad. castellana de Herder, Barcelo- 
determinada zona, y que el usurpador se apodere de este sitio, se produce el curioso fenómeno de que precisamente allí donde 'tú' estás 'nace' un lugar para mí; en lugar de cederle una posición al otro en la espacialidad prefijada de la ratio, y de la subsiguiente pérdida de espacio propio, surge el raro fenómeno de la multiplicación 'ilimitada' del espacio propio, mediante una entrega» ${ }^{63}$.

La donación anula la posesión pero multiplicando amorosamente las dimensiones insondables de la tierra prometida. La vivencia se torna convivencia, por eso no se vive ya el propio espacio en exclusiva sino que hasta el territorio y la tierra se conviven al dejar de ser espacio egoísta y covertirse en lugar de encuentro por el amor. Como lo dijo Goethe: «Siempre me eran el campo y el bosque, la roca y los jardines tan sólo un espacio, y tú, amada, los convertiste en lugar» ${ }^{64}$. El mero local objeto de disputa, odio y batalla se convierte en hogar. El espacio amoroso funde la patria terrena de la rivalidad y la envidia destructora para crear la patria eterna sin límites que permanecerá para siempre porque se ha amasado con la donación total de lo más amado y querido, la patria, el hogar primero entregado y hecho patrimonio convivencial y tierra de amor. Así adquiere el hombre, todo hombre, casa y patria.

Ahora se entiende mejor también por qué: «Entre los pueblos primitivos está muy extendida la costumbre de que el matrimonio coincide necesariamente con la construcción de la casa» ${ }^{65}$. El espacio común se convierte en hogar. Surge una nueva vida sorprendente, comienzo de un mundo nuevo. Por eso se amuebla todo con cariño. Y también la misma palabra dice el nombre de la casa y del hogar y la familia. La casa se convierte así en lugar de amor, donde el amor mora. Si no se amuebla con amor todo fallará. El arquitecto R. Neutra lo ha subrayado debidamente: una vivienda que no está hecha para el amor destruirá a los amantes en muy poco tiempo ${ }^{66}$. Ellos deben tomar precauciones.

El espacio comunitario debe forjarse con esfuerzo, cultivarse con perseverancia y amasarse en la amistad. Sólo así es posible vivir en el país alegre y feliz de la 'participación amistosa'. Este 'habitar en común' amplía la perspectiva de todos y los funde para encontrar nuevos horizontes más allá de las limitaciones materiales o personales: «Lo aclararé con un ejemplo bien simple: en todo grupo de colaboración mutua, en todo collegium (en el sentido más lato) es válido este hecho: donde domina el espíritu de la enemistad, de la desconfianza y de la rivalidad, cada cual estorba al otro, y cada uno teme que el

63. Cita de Binswanger hecha por Bollnow, O.F., Mensch, 230.

64. Cita de Binswanger hecha por Bollnow, O.F., Mensch, 236.

65. Bollnow, O.F., Mensch, 236.

66. Moles, A., Psicología del espacio. Aguilera, Madrid 1972. 
otro le desplace, que le quite el espacio, trabajo, éxito o algo similar. Pero allí donde la convivencia se constituye de modo razonable - ni siquiera es necesario que se trate de una amistad o de una simpatía acentuada - no sólo no puede hablarse de una limitación recíproca entre los colaboradores, sino al contrario, nace una superación mutua. El éxito de uno crea a la par nuevas posibilidades para la producción del otro. Aquí verdaderamente ocurre que el trabajo en comunidad crea un espacio vital que es mayor que la suma de espacios vitales individuales. La cooperación crea realmente un nuevo espacio vital» ${ }^{67}$.

La cita es un poco larga pero llena de contenido. Aquí ha quedado superada la lucha por el espacio vital y el principio territorial. Esto es edificar juntos, pensar y habitar en común, que es lo opuesto a «Una estancia meramente pasajera en un punto arbitrario del espacio. Habitar es ser 'de' un punto determinado, estar en él enraizado, 'en casa»' ${ }^{68}$. Este es el ideal del 'habitar en común unánimes en la casa' en sentido agustiniano. No se es un extraño en la casa, como perdido o encerrado en la casa sino que se pertenece a la familia, biológica o comunitaria, se es «de la casa» de Dios, Y en su casa cada cual es libre a la vez que vive totalmente unido a los demás por los lazos de la familiaridad amorosa y la amistad.

Una vez cambiado el animal por el hombre, podemos asentir también perfectamente a estas consideraciones de Portmann: «El hogar se convierte así en un lugar donde, gracias a la seguridad y la tranquilidad, los estados anímicos esenciales de todo animal superior encuentran una satisfacción máxima; es un lugar, pues, que posibilita amparo» ${ }^{69}$. Así como sólo desde el hogar es posible la fecundidad - Lorenz, Ardrey - del mismo modo solamente desde el amparo de la casa es posible la comunidad. De ahí que o se opta por la casa y la comunidad o se opta por la descomposición y la dispersión. En ese sentido, dígase de paso, los monjes golondrinas son literalmente imposibles.

Todo ello no se opone a dejar de ser unos territoriales elementales. Al contrario, la capacidad de adaptación a diversos lugares, posibilidad de generalización, como dice la antropología cultural, es una cualidad específica del hombre. $\mathrm{Y}$ en cierto modo, el hombre es de donde se encuentra y donde se encuentra es, y ahí le espera la felicidad. Dice un pasaje agustiniano que entre los bienes de este mundo ninguno es más precioso al hombre que el oro. Pues bien, el hombre entrega su oro a cambio de recibir tierras. Es decir, el territorio es el bien supremo en este mundo para el hombre. O como dice Ortega, se pierde el pueblo pero no se pierde el surco. Tal es el poder del instinto territorial humano.

67. Bollnow, O.F., Mensch, 239.

68. Bollnow, O.F., Mensch, 246.

69. Bollnow, O.F., Mensch, 263. 


\section{6. ¿Pero qué es un instinto?}

Antes de concretar más el sentido del instinto territorial, se puede estar, en principio, de acuerdo con el gran biólogo Portmann: «Como instinto se han caracterizado ya tantas cosas, al tratar de lo innato y corriente en la conducta, que los zoólogos ya no quieren oír esa palabra» ${ }^{70}$. Vale la pena reconsiderar el asunto. Se escuchan nuevas voces autorizadas sobre la existencia o no del instinto territorial. Ya son conocidas las opiniones favorables de Storr, Lorenz y Ardrey. A. Montagu, por ejemplo, dice: «Según hemos visto, Ardrey considera que este impulso inherente es genético e imposible de erradicar; pero también vimos algunas pruebas de que eso no es cierto en muchos animales, desde los peces hasta los primates no humanos. Los errores fundamentales de Ardrey son dos: el primero es suponer que los animales son territoriales con escasas excepciones, y el segundo es que, por consiguiente, los humanos tienen que ser territoriales a causa de su ascendencia animal» ${ }^{71}$.

Con cierta facilidad puede verse que las reservas de Montagu provienen fundamentalmente de una biologización excesiva, según él, del instinto territorial hasta convertirlo en una 'necesidad biológica' y 'genética', determinista, absolutamente natural y decisiva. Por otra parte acusa a Ardrey de un paso apresurado del campo de los animales al de los hombres. $Y$ además objeta que hay animales no territoriales, cosa que la mayoría de los territorialistas admiten. Parace, pues, que todas sus reservas pueden superarse con algunas pequeñas correcciones.

G. di Siena muestra grandes precauciones contra la identificación demasiado rápida de ciertas conductas humanas como los patriotismos, los nacionalismos, regionalismos y semejantes, que según él son culturales y adquiridas, con las consecuencias inmediatas de un instinto animal innato territorial. Y dice así: «Esta explicación, que tiene sú parte de verdad, corre el riesgo de tomar cómodamente los instintos humanos como fuente inmutable de cualquier acontecimiento histórico, anulando, de golpe, todo lo que hay de adquirido en las costumbres humanas y sociales; sobre todo, hace desaparecer las capacidades reactivas de las relaciones sociales al canalizar por caminos muy precisos las líneas de conducta humana» ${ }^{72}$.

Di Siena admite que, efectivamente, todos los establecimientos humanos están en áreas territorialmente marcadas. Pero cree excesiva la mecanización

70. Portmann, A., Neue Wege der Biologie. Trad. castellana de eds. Iberoamericanas, Madrid 1968. 79.

71. Montagu, A., The Nature of Human Aggression. Trad. castellana de ed. Alianza, Madrid 1978. 201.

72. DI SIENA, G., Ideologie. 34. 
de las consecuencias del instinto territorial. Además rechaza que determinadas instituciones sociales como la propiedad privada sean una mera consecuencia del instinto territorial aunque admite como objetivo fundamental del territorio la seguridad y la alimentación. Por tanto discute lo que otros autores admiten y afirma lo que otros niegan: La vinculación directa de la territorialidad con el instinto de posesión por una parte; y pone el instinto territorial en relación a la función de conservación y alimentación, cosa que otros autores no aceptarán, aun cuando convengan en que la defensa del territorio tiene también una función económica.

J.L. García cree que las cosas son mucho más complicadas de lo que parece a primera vista. Y dice: «La situación territorial de cualquier grupo humano es, pues, extremadamente complicada» ${ }^{73}$. Este autor rechaza todo modelo mecanicista en el estudio de las conductas porque piensa que «ello es debido a unas preconcepciones metafísicas de la mente humana, que hacen de ésta un constructo mecánico que opera machaconamente dentro de sus moldes binarios, impasible a las influencias que puedan provenir del exterior y, en última instancia, unificadora implacable de los más diversos materiales a ellas sometidos» ${ }^{74}$.

Evidentemente se trata de una crítica dura y muy de fondo al estructuralismo y a la infalibilidad cientificista. Pone además restricciones a las teorías de Hall, aunque acepta sus descripciones fundamentales, especialmente por causa de la diversidad de las culturas, cosa, por otra parte, que Hall también admite ${ }^{75}$.

J.L. García da mucha importancia a las actividades y la organización del grupo como medio de explicación de todo lo demás, incluido el instinto territorial. Para él: «La delimitación del espacio y su cualificación se hace en términos de una estructura social, porque en definitiva la territorialidad no es otra cosa que una perspectiva de esa estructura, la forma cómo el hombre se comporta territorialmente estaría regida por pautas aprendidas equivalentes a las que gobiernan la estructura social» ${ }^{76}$.

Quizá se debería haber distinguido un poco más entre instinto territorial y realización de dicho instinto, como se hace en otro lugar, y contraponer menos lo social y lo individual, lo exterior y lo interior, aun cuando se pueda distinguir entre territorio y dominio y dar la importancia debida a la semantización territorial. Afirma también este autor que las estructuras biológicas no

73. García, J.L., Antropología del territorio. Eds. J.B., Madrid 1976. 90.

74. García, J.L., Antropología, 91. Subrayado mía.

75. García J.L., Ibid., 128-129.

76. GARCÍA J.L., Ibid., 75-76. 
son las únicas que condicionan la territorialidad y la necesidad de interrelación entre lo físico y lo cultural. Esto distingue la territorialidad humana de la animal porque pone en juego a la vez la biología y la cultura ${ }^{77}$.

Contar con lo biofísico, solamente, sería una explicación demasiado pobre de lo humano pues: «El hombre es precisamente el animal más generalizado de cuantos existen, lo que equivale a decir que la correspondencia entre su comportamiento biológico y su medio es discontinua» ${ }^{78}$. Lo biológico ofrecería orientaciones pero no conclusiones definitivas. Sería la cultura la llamada a establecer acuerdos determinantes. Ahora bien, los ciclos naturales tienen también su gran capacidad de presión como se ve por los calendarios y las fiestas.

A pesar de todas esas observaciones que no son de poca monta y suponen toda una concepción antropológica, nuestro autor lamenta que la territorialidad sea un tema «de los más desatendidos en su verdadera significación antropológica». Para él la territorialidad «responde a unas necesidades humanas bien concretas» ${ }^{79}$. Pues «opera eficazmente y no sólo mentalmente». $\mathrm{Y}$ es bien cierto que ««el territorio es un espacio socializado y culturizado, de tal manera que su significado sociocultural incide en el campo semántico de la espacialidad humana» ${ }^{80}$.

Este mismo autor describe diversos tipos de demarcación animal y humana, según las diversas culturas, y señala los lugares fundamentales de un territorio según los clásicos de la territorialidad como Heideger ${ }^{81}$. Distingue también entre territorios exclusivos y no-exclusivos y describe un conocido fenómeno de la territorialidad humana: «Cualquiera que haya frecuentado las aulas de libre ocupación se habrá dado cuenta que existe una tendencia a la distribución en puestos fijos. Con la reiteración del uso territorial estos actos de exclusividad positiva conllevan el sentimiento de exclusividad negativa en los demás» ${ }^{82}$. Así en una biblioteca pública o en una sala comunitaria, tales o cuales sitios llegan a ser los sitios o las sillas de fulano o de zutano.

Admite también dicho autor que la desorientación territorial es una fuente inagotable de descomposición de los valores ${ }^{83}$. Las variaciones de la territorialidad modifican enormemente las conductas y las culturas, las creencias y las artes humanas. Del mismo modo se acepta que la casa y la huerta «constituyen una unidad, marcada desde el punto de vista de la territorialidad por un

77. GaRCía J.L., Ibid., 42 y 154.

78. García J.L., Ibid., 67.

79. García J.L., Ibid., 107.

80. García J.L., Ibid., 27.

81. García J.L., Ibid., 75 .

82. GARCía J.L., Ibid., 86.

83. García J.L., Ibid., 179. 
sentido de exclusividad positiva» ${ }^{84}$. Desde ese territorio la familia crea su propia imagen.

Según mi parecer, que ciertamente es discutible, este autor admite el principio territorial ante los hechos y sus consecuencias innegables pero se tiene la impresión de que lo culturiza excesivamente. Es decir, la metodología culturalista influye, al parecer, un poco demasiado en la explicación del problema.

Algunas diferencias importantes entre los distintos autores que tratan el problema quizá procedan también de una concepción básica, excesivamente rígida, acerca del instinto. Y por eso luego se rechaza el instinto territorial como realidad ya que no aparece tan determinado como se esperaba. Pero esa mentalidad no responde a la realidad científica actual. Así por ejemplo, Monod critica la atribución parcialista de toda conducta, bien sea al instinto sólo o sólo al aprendizaje. No se puede ser ya o burdamente innatista o simplemente conductista: «En nuestros días, todavía, ciertos etólogos parecen aferrados a la idea de que los elementos del comportamiento en el animal, son o bien innatos o bien aprendidos, y cada uno de estos dos métodos excluyen absolutamente al otro. Esta concepción es errónea como lo ha demostrado enérgicamente Lorenz» ${ }^{85}$. De hecho los comportamientos son innatos y adquiridos a la vez, rígidos y simultáneamente plásticos.

Toda conducta implica aprendizaje pero conforme a un programa innato. Siempre hay una dialéctica entre el genotipo y el fenotipo y no se puede privilegiar fácilmente una u otra dimensión separadamente sin caer en graves fallos. Por tanto no se puede liquidar alegremente la teoría de los instintos ni se puede prescindir ciegamente de la experiencia.

En .esta situación Lorenz ha formulado una nueva teoría que encabeza con el título de «El gran parlamento de los instintos» ${ }^{86}$ y que expone así: «Es necesario decir algo del mecanismo de los instintos, que se parece a un parlamento en que es un sistema más o menos completo de interacciones entre un gran número de variables independientes y además, porque sus procedimientos, verdaderamente democráticos, han sufrido una prueba histórica y son capaces de crear si no una armonía verdadera entre los diferentes intereses, por lo menos tolerables compromisos que hacen posible la vida» ${ }^{87}$.

Como se ve se está muy alejado de cualquier veleidad determinista y fuera de toda sospecha en lo referente a cualquier relación de amenaza del instinto a

84. GARCÍA J.L., Ibid., 213.

85. Monod, J., Le hasard et la nécessité. Essiai sur la philosophie de la biologie moderne. Seuil, Paris 1970, 167.

86. LORENZ, K., Das sogenannte, 98.

87. LORENZ, K., Ibid., 98-99. 
la vida o a la libertad del hombre. También está claro que el instinto aquí es algo más que nada, y bastante más que un simple comentario a la influencia socio-cultural. Según Lorenz, la teoría tradicional del instinto es 'finalista' y confunde el 'para qué' con el 'porqué. Con descubrir una función constante no es suficiente para afirmar que allí hay propiamente un instinto. El finalismo perfecto y el conductismo mecanicista coinciden en sus dogmatismos. Lorenz no cree tampoco que haya un instinto fundamental y otros entregados a su servicio según el modelo fundamentalista de Huxley. Se trata más bien de un parlamento formado por grupos relacionados pero independientes.

\subsubsection{Características actuales de lo instintivo.}

Una característica de lo instintivo es que no actúa sólo por estímulos externos sino que «en ausencia de tales estímulos revela su propia espontaneidad» ${ }^{88}$. Así cuando se actualiza el instinto, éste no se destruye sino que se conduce como juego. Dice Lorenz que cuando los gansos no necesitan buscar en el fondo del agua para comer se diría que «Comen para poder buscar en el fondo ${ }^{89}$. Los movimientos instintivos se realizan, siempre, de una forma $u$ otra.

En cuanto al orden y la jerarquía de los instintos Lorenz cita el hecho sintomático de que la «la voz de la sexualidad se extingue casi del todo cuando los gansos están en territorio extraño» ${ }^{90}$. Por tanto el instinto territorial es primero. En cualquier caso el instinto sigue con su invariabilidad ahí hasta que encuentra su ocación ya por estimulación interior o por simple contacto externo. Las investigaciones afirman «la constancia formal de la acción instintiva» ${ }^{91}$. Pero eso no quiere decir que el proceso instintivo se desarrolle siempre igual o de forma mecánica sino que presenta desarrollos muy diversos según las situaciones. Por ejemplo la falta de habituación eleva el umbral de sensibilización desencadenante ${ }^{92}$. Todo lo contrario, pues, de la concepción tradicionalista que creía poder controlar el proceso instintivo a base de negarle información y estímulo.

Cierto que Tolman cree que el «comportamiento animal no puede desarrollarse en el vacío». Pero Lorenz cree lo contrario ${ }^{93} \mathrm{y}$ tanto von Holst como Lorenz han demostrado razones mejores y más científicas en este asunto sin

88. LORENZ, K., Ibid., 103.

89. LORENZ, K., Ibid., 107.

90. LORENZ, K., Ibid., 114.

91. Lorenz, K., P. Leyhausen, Antriebe tierischen und menschlichen Verhaltens. Trad. castellana de S. XXI, Madrid $1976^{4 a}, 19$.

92. Lorenz, K., P. Leyhausen, Antriebe, 21.

93. Lorenz, K., P. Leyhausen, Antriebe, 24. 
confundir acción refleja y acción instintiva como suelen hacer ciertos estudiosos ${ }^{94}$. El instinto es importante para la motivación pero no se confunden, como no se puede confundir el medio con el fin, ni la educación con el mero seguimiento instințal. Si bien aquélla se apoya sobre éste que no es simplemente una carga de energía pulsional meramente mecánica: «En ello estriba la totalidad de la actividad espontánea del organismo. Si el hombre y los animales no son, como se supuso con gran seriedad durante mucho tiempo, puramente autómatas, movidos exclusivamente por reflejos, que a determinada incitación exterior siempre deben responder con la misma reacción estereotipada, esto se debe a ese automatismo pulsional» ${ }^{95}$.

El parlamento de los instintos interpreta los estímulos y «los mecanismos desencadenadores innatos (MDI) son como el teclado sobre el cual el medio ambiente interpreta la sinfonía de los instintos» ${ }^{96}$. Todo esto se expresa en el hombre de manera especial por la voluntad, que supone cierta armonización entre los impulsos y los mecanismos desencadenadores innatos (MDI) a la vez que una tonalidad debida. Ahora bien, esto no es el fatalismo porque la organización básica es fundamento de la libertad y no sólo su condicionamiento. De hecho toda la mecánica instintiva se independiza, en cierta manera, del exterior: «Únicamente a ella debemos esa independencia respecto a la situación externa, que nos posibilita obrar espontáneamente» ${ }^{97}$.

Para Leyhausen el MDI (mecanismo desencadenador innato) es como «la voz de Dios» en el hombre, el fundamento innato de la conciencia moral que ni el ambiente ni siquiera el educador puede descomponer (la conciencia es incorruptible e insobornable). Ese MDI no es aún el troquelado donde se practican los esquemas elementales de las elecciones concretas del futuro. Todos esos niveles: Impulso, MDI, troquelado han padecido rupturas más o menos graves que el hombre refleja como división interior. Pero a pesar de todo, no está determinado a priori «qué relación de fuerzas pulsionales será activada» ${ }^{98}$.

Es la formación de la persona la que establece las alternativas en elecciones apropiadas, y cooordina unos sectores con otros para que incluso las fuerzas de tensión adversa se conviertan en elementos positivos. Se trata por tanto

94. LoRenZ, K., P. Leyhausen, Ibid., 27.

95. LorenZ, K., P. Leyhausen, Ibid., 59. Además «Las coordinaciones instintivas, en efecto, se mantienen puras y con plena capacidad funcional junto a todo lo aprendido»: LORENZ, K., P. Leyhausen, Antriebe, 237. MANNING, A., An introduction to animal behavior. Trad. castellana de Alianza, Madrid $1975^{3 a}$ 97-106.

96. LoRenZ, K., P. Leyhausen, Antriebe, 63.

97. Lorenz, K., P. Leyhausen, Ibid., 69, El MDI dirige y coordina todo: Tinbergen, N., A Study of Instinct. Trad. castellana de S. XXI, Madrid 1975, 203.

98. Lorenz, K., P. Leyhausen, Antriebe, 75. 
de llegar a un equilibrio de fuerzas activas. En este caso: «La voluntad es una función compensadora o equilibradora de los impulsos con ayuda de la razón y el intelecto y a través de los MDI para exigir un mundo superior de valores; dominio de sí mismo significa dominio de unos impulsos mediante otros impulsos» ${ }^{99}$. Por eso el niño en la educación a veces necesita encontrar resistencia física.

Los impulsos están además unidos al juego ${ }^{100}$. Todo instinto es en cierto modo un juego que hay que aprender, descifrar y practicar. Siempre hay en el instinto un sentido de fin eficaz pero también un valor estético de despliegue placentero ${ }^{101}$. Eso amplifica el número de intereses nuevos con una especie de multiplicación diversificada de los instintos y su armonización hasta crear a veces la impresión de desintegración o transformación del instinto ${ }^{102}$. Este es precisamente un momento decisivo para la aparición del hombre en su diferencia específica. Pero no hay que volver a contraponer lo instintivo y lo espontáneo, puesto que se complementan, exactamente igual que sin la necesidad no habría juego y azar.

Un instinto es como una melodía que se ejecuta y tiene su secuencia interna propia aunque también haya muy diversas interpretaciones exteriores que a veces parecen desfigurar la secuencia interna. Pero ahí está la creatividad del artista, en saber llegar a hacer de la necesidad virtud, es decir, valor apropiado, espontáneo y libre.

En cualquier caso no hay que mirar el instinto solamente como restricción sino también como apoyo. La resistencia del aire es lo que permite a la paloma kantiana volar, sin esa oposición capota. El instinto y lo biológico son la base de apoyo de la libertad, si bien no son la libertad misma. Con demasiada frecuencia «Se ha llegado a demonizar el instinto (la pulsión), se le ha concebido como el enemigo de la libertad humana y se ha visto en su superación la meta principal de la evolución humana. Basándose en esta actitud de principio se ha discutido o, más bien, negado la naturaleza instintiva de todas las pretendidas 'tendencias superiores' del hombre; (así) los instintos son 'impulsos bajos'»103.

Por el contrario, según von Holst en el instinto más que de un 'tener que' se trata de un 'poder', es «un estímulo a lo que el organismo puede reaccionar, pero no tiene forzosamente que hacerlo» ${ }^{104}$. Gracias a esto el hombre es un

99. LORENZ, K., P. LeyHAUSEN, Ibid., 79.

100. LoRenZ, K., P. Leyhausen, Ibid., 241 y ss.

101. Lorenz, K., P. Leyhausen, Ibid., 249.

102. LORENZ, K., P. Leyhausen, Ibid,, 255 y ss.

103. LORENZ, K., P. Leyhausen, Ibid., 277.

104. Lorenz, K., P. Leyhausen, Ibid., 277. 
ser libre y espontáneo, no un animal regido por la binariedad estímulorespuesta. Se observará fácilmente que este último esquema es el que se trae siempre a cuento de la sexualidad con la palabra represión, mientras que cuando se trata del instinto de agresión se penalizan esas mismas conductas de respuesta inmediata.

Se trata evidentemente de concepciones anticuadas que quieren colarse por modernas cuando se trata del campo sexual. Por tanto: «La vieja opinión basada en concepciones antiguas — como la de Ziegler que concebía el instinto como una cadena de reflejos - rígido como el de un autómata, se refiere únicamente a casos límite y no es la regla, sobre todo tratándose de animales superiores» ${ }^{105}$. Todo instinto puede ser orientado y educado pero nunca amaestrado.

Del mismo modo si el instinto puede desplegarse en instituciones superiores que puedan promover el reconocimiento mutuo de los seres humanos y lograr que de modo permanente los individuos adapten su comportamiento en el marco de estas instituciones es porque existe una fundamento instintivo para ello, porque la institución garantiza al individuo la satisfacción de sus instintos en un marco y unas proporciones adecuadas: «Cuando las instituciones comienzan a cobrar un desarrollo autónomo y a alejarse demasiado de su fundamento instintivo, se levantan por lo regular quejas contra la maldad de la naturaleza humana y exigencias para cambiarla» ${ }^{106}$.

Desde esta concepción todo es más fácil y cada uno puede hacer sus propias aplicaciones. Las mismas reacciones innatas se sabe que son selectivas y las actividades instintivas son mucho más complejas de lo previsto ${ }^{107}$. Por lo mismo tampoco se puede oponer lo innato a lo espontáneo ${ }^{108}$ hasta desarrollar lo instintivo inadecuadamente ${ }^{109}$. Por otra parte sería bueno que del hombre se pudiera decir algo bien conocido entre los animales: «es un hecho muy notable e importante que la 'lucha' entre los animales suele consistir en la amenaza o fanfarronada» ${ }^{110}$; y así no fuera, entre los humanos, una realidad sangrienta. De hecho los instintos pueden reorientarse y tienen capacidad de desplazamiento y reorganización. Así la agresión puede orientarse por caminos no sangrientos ${ }^{11}$.

105. LORENZ, K., P. LEYHAUSEN, Ibid., 294.

106. Lorenz, K., P. Leyhausen, Ibid., 301.

107. Tinbergen, N., The Study of instinct. Trad. castellana de S. XXI, Madrid $1975^{3 a}, 10$.

108. TINBERGEN, N., Ibid., 83.

109. Tinbergen, N., Ibid., 174.

110. Tinbergen, N., Ibid., 230-232.

111. LAVER, J., «La indumentaria como medio de agresión social», EBLING J., M. CARTHY, The natural history of aggression. Trad. castellana de S. XXI, Madrid $1977^{4 a}, 150$ y ss. 
No hay mecanicismo instintivo como no hay división total entre 'cultura, vida y realidad físico-química': «No es solamente el hombre el que no puede reducirse a la biología, es la misma biología la que no puede reducirse a biologismo» ${ }^{112}$. El hombre es un ser especial que no puede reducirse al biologismo ni al idealismo desterrado. El hombre, la vida y el mundo son «sistemas abiertos» ${ }^{113}$, y no simples funcionarios de la ciencia. Las últimas investigaciones hablan de una dialéctica entre unidad y diversidad, permanencia y cambio, probabilidad e improbabilidad, etc ${ }^{114}$. También se afirma el fin de los paradigmas seguros y se presenta la vida como un sistema dinámico y complejo; hay una relación entre lo fenoménico y lo genotípico de incertidumbre biológica y se apunta a la «lógica ilógica de lo viviente» ${ }^{115}$ abierta a la complejidad de lo real.

Atrás quedan, por tanto, las posiciones rigoristas deterministas así como las conductistas liquidadoras de todo lo instintivo. Y autores también como Lehrmann que no creen susceptible de verificación lo instintivo e insisten solamente en la adaptación como justificación de todas las cosas ${ }^{116}$. Hay que reconocer, por tanto, una cierta realidad instintiva, sin dejar de aceptar por eso la importancia de los procesos debidos al medio ambiente; del mismo modo que el principio de indeterminación en la ciencia actual de ningún modo supone afirmar que toda la ciencia actual es puro azar sin ninguna lógica. En ese caso la ciencia sería imposible como ha visto muy bien M. Bunge ${ }^{117}$.

Del mismo modo el rechazo de la seguridad objetiva presupuesta por $\mathrm{Ga}$ lileo y Descartes no es la afirmación de una ciencia inválida y carente de toda objetividad ${ }^{118}$. Por el contrario, la ciencia actual, tan dubitante en muchos aspectos, es mucho más objetiva que la seguridad presumida de los siglos anteriores. La duda ha sido muchas veces fuente notable de ciencia y sabiduría frente a la vana credulidad sin fundamento.

112. MoRIN, E., Le paradigme perdue: La nature humaine. Seuil, Paris 1973, 58.

113. Morin, E., Ibid., 234. Aunque con grabaciones y engramas todos admiten, al menos en parte, sistemas abiertos. En estos términos se explica también el conocidísimo D. Morris. Otros hablan de variación y retención: CAMPBELL, D.T., «Variación injustificada y retención selectiva en los descubrimientos científicos»: AYALA, F.J., Estudios sobre la filosofía de la biología. Ariel, Barcelona 1983, 200.

114. Morin, E., La Methode I. La nature de la Nature. Trad. castellana de eds. Cátedra, Madrid 1981. Cfr. también Rosset, C., L'Antinature. P.U.F., Paris 1973.

115. Morin, E., La methode II. La vie de la Vie. Trad. castellana de eds. Cátedra, Madrid 1983, 150, 323, 446.

116. LORENZ, K., Ueber tierisches und menschliches Verhalten. Trad. castellana de Plaza Janés, Barcelona 1976, 339 y ss. LerhmANN, D.S., N. TinBergen, Kritik der Verhaltensforschung: Konrad Lorenz und seine Schule. Beck, München 1974, 17 y 55.

117. Bunge, M., F. Halbwachs, Las teorías de la causalidad. Trad. castellana de eds. Sígueme, Salamanca 1977, 65.

118. Monod, J., Le hasard, 33. 


\subsection{Para no concluir: Instinto territorial y autonomías}

Puede que, en principio.y para algunas personas, asegurar que el hombre es un ser territorial constituya una especie de ofensa sin más. Pero hoy nadie considera un agravio la previsión de conductas sociológicas o de movimiento de masas. Cierto que los humanos a veces obran demasiado instintivamente, e incluso en el sentido más tradicional del instinto. Pero les resulta muy difícil, por no decir imposible, reconocerlo. No se quieren ya reconocer ni admitir ni siquiera las mínimas leyes naturales para ninguna conducta: «B. Hassenstein ha denominado a esto 'juicio axiológico anti-causal» ${ }^{119}$. En último caso se echa la culpa a agentes exteriores, dejando siempre a salvo la propia estima. Tampoco se trata de que todo sea pura mecánica.

Aquí se afirma que el hombre tiene un instinto territorial, marca un territorio y lo defiende. Por eso, puede ser amable con los suyos y un demonio con los extraños. Si no se reconoce esto se caerá en la ingenuidad de confiarlo todo a la moralidad responsable. $\mathrm{O}$, lo que sería peor, a la afirmación terca de las propias razones infalibles e intocables por estar uno defendiendo algo tan elemental e intocable como su patria, su propia tierra o región, y en definitiva su familia y su casa.

Es sabido que el hombre por su territorialidad crea sus propios dominios -en continuidad con su casa-, sus predios y su patria chica a la que considera insultada por un simple 'arriba tal y tal' o 'abajo los de cual'. O simplemente se considera invadido o cercado por cualquier causa. No hace falta decir que esto es un insulto a los verdaderamente oprimidos.

Sin tener todo esto en cuenta, los valores morales se descomponen inesperadamente muy deprisa ${ }^{120}$. Un instinto, por ejemplo el territorial, exaltado arbitrariamente $u$ oprimido insensatamente puedé conducir a verdaderos estragos. Mientras que un instinto reconocido y atendido puede ser debidamente orientado. Lorenz, que parece tan territorialista, no duda en afirmar: «Las normas del comportamiento social creadas por la ritualización cultural desempeñan en la sociedad humana un papel tan importante como la motivación instintiva y el control que ejerce la moral responsable» ${ }^{121}$.

Del mismo modo, la orientación de la agresividad territorial por vías positivas para la humanidad es una invención genial de la naturaleza ${ }^{122}$. Sería por tanto bueno que también al instinto territorial se le encauzase por la vía de

119. LORENZ, K., Das sogenannte, 245.

120. LORENZ, K., Ibid., 287.

121. LORENZ, K., Ibid., 291.

122. LORENZ, K., Ibid., 68 y ss. 
los buenos modales, lo que los sociólogos llaman cohesión de grupo, y hoy, con mayor sentido de la libertad, se puede llamar solidaridad.

Todo el mundo acepta el patriotismo, al menos el de su patria aunque uno no sea patriotero. A primera vista parece que no faltan personas que creen tener la exclusiva de las lealtades a tal o cual nación o a tal o cual tierra. Cierto que la patria chica, la pequeña patria es digna de todos los fervores y dedicaciones hasta convertirse en el propio centro del mundo ${ }^{123}$; pero no sería humano olvidarse de los otros pueblos.

Igualmente se requiere hoy una atención más cuidadosa, por parte de los estatalismos apresurados que olvidan fácilmente la diversidad de lengua, educación, política, paisaje y agriculturas ${ }^{124}$, para una mejor valoración de todas las potencialidades y posibilidades sorprendentes de los grupos humanos. El Estado debe ser más un apoyo a las comunidades territoriales que simplemente un poder. De la misma manera las comunidades humanas deben ser profundamente solidarias ${ }^{125}$. Y no solamente de palabra sino también de obra. Sólo así es posible hermanar las posibilidades de las diferentes naciones y pueblos hasta plenificar y «distribuir los beneficios de la cultura humana» ${ }^{126}$ al servicio de todos sin exclusión.

No se puede exaltar de modo insensato el principio territorial, ello llevaría, a la larga, a consecuencias desastrosas y fanáticas, aun cuando de inmediato reportase beneficios particulares a un determinado grupo. Tampoco es posible domesticar este instinto. Así, se le desorienta en un autonomismo «recalcitrante» que se identifica demasiado fácilmente con «sectionalism or separatism» ${ }^{127}$.

No es tan sencillo como parece negar el instinto territorial o hacer como si no existiera. Desgraciadamente la cruda realidad se encarga de despertar rápidamente a los ingenuos y a los supuestamente optimistas.

Ahora bien, el principio territorial, debidamente cultivado lleva en sí potencialidades enormes de creatividad, solidaridad, humanidad y ternura como lo demuestra la historia de las culturas regionales y de los diferentes pueblos y naciones. Cierta violencia, es más bien un accidente, o responsabilidad humana concreta, en el desarrollo de la territorialidad que, como todos los instintos, tiene sus problemas y dificultades de orientación y realización concreta. El sentido de fratría, de tarea común, del primor de las costumbres, el variable colorido de los folklores y sobre todo las profundidades del alma de cada pue-

123. Mumford, L., The culture of cities. H.B. Jovanovich, New York 1970, 355.

124. MUNFORD, L., Ibid., 359.

125. MuMFord, L., Ibid., 364.

126. MUMFORD, L., Ibid., 364.

127. MUMFORD, L., Ibid., 351. 
blo demuestran o al menos indican que también un día el Estado y la humanidad llegarán a ser una «comunidad de comunidades» donde cada una y cada cual aporte toda la riqueza de sus propios valores.

El instinto territorial ha de quedar así orientado más por el amor a la propia tierra que por la rebelión ante la patria herida. Esa herida, dramática, del instinto territorial es muy difícil de curar y sólo pueden tratarla manos muy delicadas. Es preciso que cuantos se mueven en estos ámbitos lo hagan con toda la delicadeza de la mejor y mayor humanidad para orientar sin herir hasta que la esperanza de construir un mundo nuevo sea patrimonio común en la vida de todos y cada uno; de los individuos y de los pueblos.

Tal vez hasta tiempos muy recientes no se ha escuchado suficientemente la voz autorizada del instinto territorial, pero eso naturalmente no ha inpedido que las regiones, los pueblos, las comarcas y las provincias y «En cada una de ellas, los hombres, fieles al medio en que viven, se han creado un modo de ser, como si cada tierra tuviese un misterioso poder, que no han conseguido explicar los sabios, de crear un tipo de ser viviente que obedece a una unidad de estilo; cual si fuese la tierra un escultor que imprimiese su sello en las figuras que crea» ${ }^{128}$.

Cierto que al verse desatendidos los hombres y los pueblos, en sus grandes aspiraciones, tan profundas, ocurrió lo que debió de ocurrir: «El resultado fue que en las provincias surgió el descontento hacia aquel Estado centralizado, al que culpaban de todos los incidentes enojosos que acontencían en la localidad, y se habían insolidarizado de aquella estructura nacional» ${ }^{129}$.

Será necesario prestar una atención mucho más esmerada a todos estos procesos, especialmente ahora que ya se han cumplido algunas previsiones necesarias: «Yo imagino una España nueva constituida en grandes unidades regionales, cada cual con su Gobierno local y con su Asamblea comarcana de sufragio universal» ${ }^{130}$.

Ahora los hombres y los pueblos tienen por delante una tarea ingente que precisa de las mejores energías humanas $y$ materiales. La territorialidad y sobre todo los hombres y pueblos, con su vivir y sus tierras, son una llamada clamorosa a un esfuerzo solidario de todos hasta una confraternización libre y dedicada de todas las naciones en todo el mundo.

\section{DOMINGO NATAL}

128. ORTEga Y GASSET, J., «Discurso en León». Obras completas, 11. Alianza, Madrid $1983,304$.

129. . Ortega y GASSET, J., «Discurso en León». Ibid., 304.

130. ORTEga y Gasset, J., «Proyecto de Constitución». Ibid., 372. 